\title{
BMJ Open Change in prevalence rates of physical and sexual intimate partner violence against women: data from two cross- sectional studies in New Zealand, 2003 and 2019
}

\author{
Janet Fanslow (D) , ${ }^{1}$ Ladan Hashemi, ${ }^{1}$ Zarintaj Malihi, ${ }^{1}$ Pauline Gulliver, ${ }^{1}$ \\ Tracey Mclntosh ${ }^{2}$
}

To cite: Fanslow J, Hashemi L, Malihi Z, et al. Change in prevalence rates of physical and sexual intimate partner violence against women: data from two cross-sectional studies in New Zealand, 2003 and 2019. BMJ Open 2021;11:e044907. doi:10.1136/ bmjopen-2020-044907

- Prepublication history for this paper is available online. To view these files, please visit the journal online (http://dx.doi org/10.1136/bmjopen-2020044907).

Received 18 September 2020 Revised 25 February 2021 Accepted 26 February 2021

\section{Linked}

- http://dx.doi.org/10.1136/ bmjopen-2020-044910

Check for updates

(c) Author(s) (or their employer(s)) 2021. Re-use permitted under CC BY-NC. No commercial re-use. See rights and permissions. Published by BMJ.

For numbered affiliations see end of article.

Correspondence to

Dr Janet Fanslow;

J.Fanslow@auckland.ac.nz

\section{ABSTRACT}

Objectives To explore changes in reported prevalence of physical and sexual intimate partner violence (IPV) between 2003 and 2019. The impact of sociodemographic differences between the two samples and between group differences were also examined. Changes in attitudes supportive of violence and in help-seeking behaviour following disclosure were also explored.

Design Two cross-sectional studies.

Setting and participants Cross-sectional studies on family violence conducted in New Zealand in 2003 and 2019. Ever-partnered female respondents aged 18-64 years old were included $(2003 n=2674,2019 n=944)$. Main outcome measures Prevalence rates of lifetime and past 12-month physical and sexual IPV, attitudes towards gender roles and acceptability of a man hitting his wife, help sought and received following disclosure were compared between the study years.

Results Lifetime prevalence of physical IPV was unchanged between 2003 and 2019 (AOR=0.89; 95\% $\mathrm{Cl} 0.73$ to 1.08). There was a significant decrease in the proportion of women who reported experiencing 12-month physical IPV (AOR=0.53; $95 \% \mathrm{Cl} 0.29$ to 0.97). Small reductions in rates for lifetime sexual IPV were also observed (AOR $=0.74 ; 95 \%$ $\mathrm{Cl} 0.59$ to 0.95). In 2019, fewer women agreed with one or more statements supportive of traditional gender roles (48.1\% (95\% Cl $45.7 \%$ to $50.5 \%$ ) in $2003 ; 38.4 \%(95 \% \mathrm{Cl}$ $33.8 \%$ to $43.2 \%$ ) in 2019). A significant decrease was noted in the proportion of women who sought help from informal sources (from $71.3 \%(95 \% \mathrm{Cl} 68.1 \%$ to $74.2 \%$ ) in 2003 to $64.6 \%(95 \% \mathrm{Cl} 58.7 \%$ to $70.1 \%$ ) in 2019). No significant changes in seeking help from formal sources, or perceived helpfulness from any source were noted.

Conclusion While the reductions in 12-month physical and lifetime sexual IPV are positive, prevention efforts need to be established, maintained and strengthened to address the substantial lifetime prevalence of IPV. Efforts to strengthen responses from formal and informal sources continue to be needed.

\section{INTRODUCTION}

Intimate partner violence (IPV) has been reported by the UN Secretary-General (2006)

\section{Strengths and limitations of this study}

- The current investigation used large, representative samples of women from population-based surveys in 2003 and 2019.

- Regular and comparable surveys of violence exposure, agreement with attitudes supportive of violence and help-seeking behaviours provide an understanding of the effectiveness of populationbased policies and programmes.

- True prevalence estimates may be higher as it is expected that women in severely abusive relationships would be unable or unwilling to participate in both surveys.

- Observed changes may reflect societal changes or environmental factors not considered in this investigation.

- Regular and comparable surveys of violence exposure are required to determine if the observed changes are sustained and represent a trend.

as 'the most common form of violence experienced by women globally'. ${ }^{1}$ IPV includes physical and sexual violence, as well as psychological abuse, controlling behaviour and economic abuse.

Efforts to respond to IPV in high-income countries include the introduction of legislation or national action plans, and strengthening the non-for-profit sector to respond to the violence experienced. ${ }^{2}$ However, the effectiveness of these strategies is not clear, as there is a lack of consistent and reliable data available to monitor changes in the prevalence of IPV over time.

The limited research available tends to rely on analysis of IPV homicide data, or other forms of administrative data from agencies such as health providers, police or courts. ${ }^{2}$ While providing useful insights, these data do 
not reflect the magnitude of the problem at the population level, as many who experience IPV frequently do not present to services, or the underlying cause of their presentation may not be identified or recorded. ${ }^{23}$

Other attempts to measure changes in IPV occurrence over time have relied on data from general crime victimisation surveys, ${ }^{4}$ but the overall framing of these questionnaires (ie, surveys about 'crime') tends to lower the reporting of the violent behaviours within intimate relationships. ${ }^{23}$ Surveys conducted for other purposes (eg, health surveys) which include a dedicated module on family violence provide some information, but can also be problematic, as space limitations for specific modules means that they might not be able to include questions that canvas the full range of violent experiences. ${ }^{5}$

The emerging consensus is that population-based stand-alone surveys are the instruments of choice' for collecting statistics on violence against women. ${ }^{6}$ To date, specific violence against women surveys have been carried out in several high-income countries (eg, USA, ${ }^{7}$ Canada, ${ }^{8}$ Australia, ${ }^{9}$ European Union, ${ }^{10}$ Finland, ${ }^{11}{ }^{12}$ Spain, ${ }^{13}$ New Zealand $\left.^{14}\right)$. However, with the exception of Australia and Finland, the surveys have generally been one-off efforts and thus do not allow for time-related comparisons. Without regular, comparable surveys, it is not possible to determine if there are overall changes in the occurrence of IPV, or if there are differential patterns of change for specific subgroups within the population.

According to the $\mathrm{WHO}$, violence results from the complex interplay between individual, relationship, social, cultural and environmental factors. ${ }^{15}$ The ecological model has been important in helping determine risk and protective factors associated with violence occurrence, but also holds promise for prevention, as it carries the assumption that changes in contributing factors can potentially lead to changes in prevalence. ${ }^{16}$ To date, the limited research that has explored differences in the prevalence of IPV over time has suggested that population-level changes in demographic factors, such as shifts in age, education, relationship status, and socioeconomic factors may contribute to the observed prevalence changes. ${ }^{4617} 18$ However, changes in environmental and social norms that may condone or help perpetuate violence, and associated effects on violence occurrence have received scant attention in the research.

Community-level norms, such as acceptance of 'traditional' gender roles and beliefs in the justification of 'circumstances in which it is acceptable for a man to hit his wife' are associated with perpetration of IPV. ${ }^{19}$ In some countries, women's acceptance of these attitudes has been found to be associated with increased risk of IPV victimisation. ${ }^{20}$ For these reasons, attitudes have been a key target of community education campaigns aimed at preventing violence against women. ${ }^{21}$ However, to date, there has been little examination of the effectiveness of these initiatives at changing attitudes, or on any associated changes in violence rates. ${ }^{21-23}$
New Zealand is one of few high-income countries where more than one comprehensive population-based survey of violence against women has been conducted: the first survey was conducted in 2003, and the second survey in 2019. Between the two surveys, a series of actions were taken to address family violence including; legislation (eg, amendments to family violence law and protection for victims act), and prevention campaigns (eg, the Family Violence: It's not ok national campaign, and the Accident Compsensation Corporation (ACC)-funded Mates and Dates high schools programme on healthy relationships). Many of these initiatives have focused on addressing physical and sexual violence and have included strong messaging about the importance of help-seeking by those experiencing violence. Comparable surveys on attitudes supporting violence over time may provide evidence about the impact of such campaigns at the population level.

In the current study, using data from two New Zealand cross-sectional population-based surveys we aimed to: (1) describe changes in the reported prevalence rates of physical and sexual IPV between 2003 and 2019, (2) examine whether changes in women's sociodemographic characteristics were associated with changes in IPV prevalence rates, and (3) determine whether changes in the reported prevalence rates were consistent across population subgroups. We also sought to determine if there were (4) changes in attitudes supportive of violence and (5) changes in help-seeking by those who reported experiencing IPV.

\section{METHOD}

\section{Procedure and participants}

Data were drawn from two cross-sectional studies on family violence conducted in New Zealand in 2003 and 2019. A comprehensive description of the methods used in the 2003 and 2019 surveys has been previously presented. ${ }^{1424}$ A brief description of the two surveys is presented here.

The 2003 study was conducted in Auckland and Waikato regions. For the 2019 study, Northland was also included in the sampling.

Sampling strategies were similar in both surveys. A population-based cluster sampling scheme with a fixed number of dwellings per cluster was used for both studies. Primary sampling units (PSUs) were based on meshblock boundaries which contain between 50 and 100 dwellings. The starting point consisted of a randomly selected street and street number within each PSU. Interviewers made up to seven visits to each selected household to identify and recruit study participants. Non-residential, aged-care and short-term residential properties were excluded from both surveys. Interviewer training and support procedures were comparable across survey waves.

\section{Eligibility}

To be eligible to participate in the survey, household members needed to be able to speak conversational 


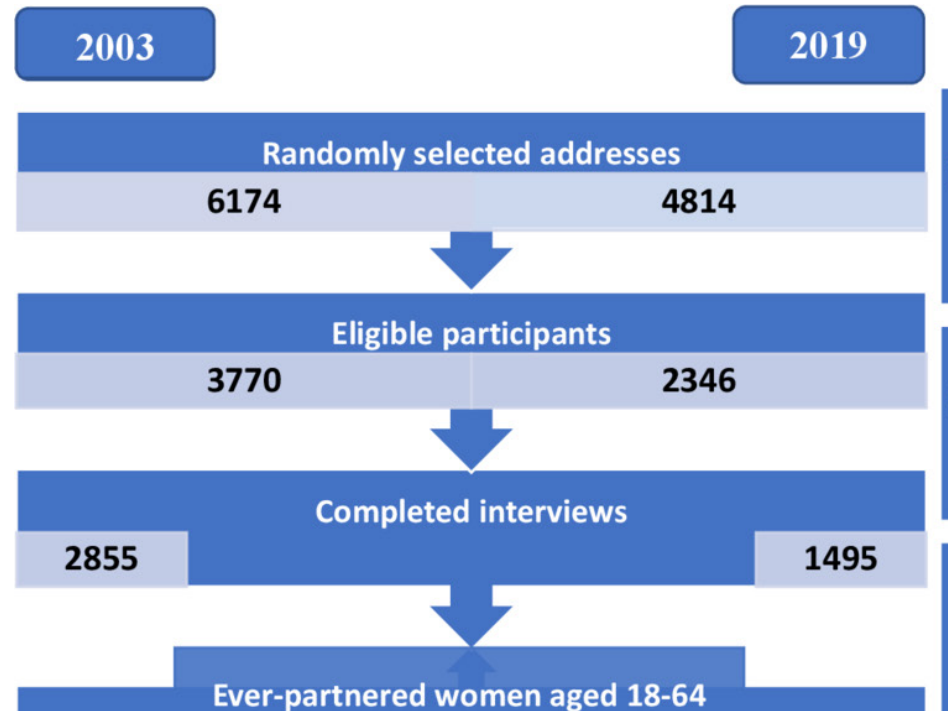

2,404 in 2003 and 2,468 in 2019 Dwelling inaccessible/vacant/not home/ language barrier/ participants were not eligible/ incapacitated/unavailable

915 participants in 2003 and 851 in 2019 refused to participate or did not complete interviews

181 in 2003 and 95 in 2019 (out of 1039 heterosexual women aged 18-64 years) were never partnered so were excluded from current analysis.

\section{4}

*For the purpose of this paper, we only included women aged 18-64 years from the 2019 survey.

Figure 1 Flow diagram of female participants in the 2003 and 2019 population-based studies on family violence in New Zealand.

English, have lived in the household for at least 1 month and slept in the house for four or more nights a week.

Of the households invited, $88.3 \%$ in 2003 and $78 \%$ in 2019 agreed to participate. Of the eligible women, $75.8 \%$ in 2003 and $63.7 \%$ in 2019 participated, yielding an overall response rate of $66.9 \%$ in 2003 and $63.7 \%$ in 2019 . Figure 1 demonstrates the number of people invited and those who were interviewed and included in the analyses for each survey year.

Participants of the 2003 study were 2855 women aged 18-64 years. In 2019, the eligible population was expanded to include women and men aged 16 years and older resulting in 2888 completed interviews $(n=1464$ women, $n=1423$ men, $n=1$ other). For the purpose of this paper, only ever-partnered women aged 18-64 years from each sample were included, equivalent to almost $94 \%$ of all women aged 18-64 years surveyed in both waves (2003, $\mathrm{n}=2674 ;$ 2019, $\mathrm{n}=944$ ).

\section{Representativeness}

In both surveys, the ethnicity, marital status, and arealevel deprivation distribution of the samples were closely comparable to the general population; however, both samples were under-represented for younger women (ages 20-29 in 2003, 16-29 in 2019). ${ }^{14}$ Demographic characteristics of ever-partnered women aged 18-64 years in the 2003 and 2019 surveys are presented in table 1.

\section{Safety and ethics considerations}

Ethics and safety recommendations for research on violence against women were followed throughout the research. ${ }^{25}$ One individual was randomly selected from each household for the interview. In households with more than one eligible resident, the participant was randomly selected. Interviews were conducted in privacy with no one over the age of 2 years present. At the completion of the interview, interviewers provided all respondents with a list of approved support agencies regardless of disclosure status. Written informed consent was obtained from all participants.

\section{Patient and public involvement}

No patients or members of the public were involved in the design, conduct or reporting or dissemination plans of our research.

\section{Study instrument and measures}

To collect data, the WHO Multi-Country Study on Women's Health and Domestic Violence Against Women ${ }^{26}$ was used in both surveys.

'Intimate partners' included male current or ex-partners that the women were married to or had lived with, or current regular male sexual partners. Definitions are presented in online supplemental table 1 for: physical and sexual IPV; sociodemographic characteristics; attitudes towards gender roles, acceptance of attitudes justifying 
Table 1 Demographic characteristics of ever-partnered women aged 18-64 years in 2003 and 2019 surveys

\begin{tabular}{llll}
\hline & $\mathbf{2 0 0 3}$ & $\mathbf{2 0 1 9}$ & P value \\
\hline Total sample & $\mathrm{n}=2674$ & $\mathrm{n}=944$ & \\
Age categories & $\mathrm{n}(\%)^{\star}$ & $\mathrm{n}(\%)^{\star}$ & 0.001 \\
$18-24$ & $182(8.6)$ & $45(6.7)$ & \\
$25-34$ & $581(21.9)$ & $169(17.4)$ & \\
$35-44$ & $857(30.2)$ & $218(21.5)$ & \\
$45-54$ & $637(24.6)$ & $268(30.8)$ & \\
$55-64$ & $414(14.7)$ & $244(23.3)$ &
\end{tabular}

\begin{tabular}{|c|c|c|c|}
\hline \multicolumn{3}{|l|}{ Relationship status } & \multirow[t]{5}{*}{0.4} \\
\hline Married & $1685(61.4)$ & 601 (63.3) & \\
\hline Cohabiting & $574(22.1)$ & $201(21.2)$ & \\
\hline $\begin{array}{l}\text { Divorced/separated/ } \\
\text { broken up }\end{array}$ & $353(14.3)$ & 117 (12.6) & \\
\hline Widowed & $60(2.1)$ & $25(2.9)$ & \\
\hline $\begin{array}{l}\text { Education } \\
\text { attainment }\end{array}$ & & & 0.001 \\
\hline Primary/secondary & $1478(55.2)$ & $315(34.8)$ & \\
\hline Higher & $1187(44.8)$ & $625(65.1)$ & \\
\hline $\begin{array}{l}\text { Independent } \\
\text { income }\end{array}$ & & & 0.0007 \\
\hline Yes & $2122(79.5)$ & $696(72.5)$ & \\
\hline No & $551(20.4)$ & $248(27.0)$ & \\
\hline $\begin{array}{l}\text { Area-level } \\
\text { deprivation }\end{array}$ & & & 0.1 \\
\hline Least deprived & $914(33.6)$ & $270(26.8)$ & \\
\hline Moderately deprived & $1045(38.8)$ & $393(39.8)$ & \\
\hline Most deprived & $708(27.5)$ & $281(33.4)$ & \\
\hline
\end{tabular}

Data are $\mathrm{n}(\mathrm{Col} \%)$.

*Weighted \% are presented.

a man hitting his wife, and sources of help sought (who was told about the IPV) and help received (sources who provided help). All questions used for analyses were identical in the two surveys.

\section{Analytic procedure}

To explore whether there were any underlying differences in demographic characteristics of the respondents at the two time periods, the 2003 and 2019 samples were compared in terms of age, relationship status, education attainment, access to an independent source of income, and area-level deprivation using $\chi^{2}$ tests.

Then, the prevalence rates of physical and sexual IPV were compared between two samples with results presented as percentages with 95\% CIs. As the results for 'moderate' and 'severe' physical IPV showed similar patterns to any physical IPV, in the following analyses, only the results for any physical IPV are presented. Any act of sexual IPV was considered as severe. To identify evidence of differences in the estimated prevalence over time, ORs and 95\% CIs for reported experience of physical and sexual IPV were calculated using univariate logistic regression models, with the study year as the predictor. The same procedure was followed for assessing differences in women's attitudes towards gender roles, attitudes towards acceptability of a man hitting his wife, help sought, and help received between the study years. For help-seeking variables, the analyses were restricted to women who reported lifetime experience of physical or sexual IPV only.

Then, to determine if the noted differences in the prevalence rates of IPV between the two study years found in the univariate analyses remained significant after controlling for sociodemographic characteristics, the following steps were taken:

- First, the association between each sociodemographic characteristic and each type of IPV (lifetime or 12 month physical and sexual IPV) was explored using univariate logistic regression models with results presented as unadjusted ORs with 95\% CIs.

- Second, multivariate analyses were conducted, with the study year and sociodemographic characteristics included, and results were presented as adjusted ORs (AOR) with $95 \%$ CIs.

Finally, to determine whether the noted changes in the reported prevalence rates were consistent across population subgroups, multivariate logistic regression models with interaction terms (between each sociodemographic characteristic and the study year) were tested. Potential confounders (eg, age, education, relationship status, independent income, and area-level deprivation) and the study year were included in these analyses.

All analyses were performed on a pooled dataset of the two samples. Missing data including: do not know, do not remember, and no responses were excluded from all analyses. Less than $4 \%$ of any variable had missing data in both surveys. All analyses were conducted using Stata/ SE V.15.1 ${ }^{27}$ survey commands to allow for stratification by sample location (region), clustering by PSUs, and weighting of data to account for the number of eligible participants in each household.

\section{RESULTS}

Differences between two study samples in terms of sociodemographic characteristics are presented in table 1. In general, there were more women over 45 years in 2019 (51.4\%) compared with 2003 (39.3\%). Additionally, a higher proportion of the sample had attained tertiary education in 2019 (65.1\%) compared with $44.8 \%$ in 2003. A smaller proportion of women in 2019 reporting having an independent source of income $(72.5 \%)$ compared with $79.5 \%$ in 2003.

\section{Physical IPV}

Changes in physical IPV prevalence rates

Lifetime physical IPV prevalence: the lifetime prevalence of physical IPV remained relatively unchanged between 
2003 and 2019, with almost $30 \%$ of ever-partnered women aged 18-64 reporting having experienced at least one episode of physical violence (table 2). After controlling for sociodemographic factors, adjusted AORs showed no significant difference in the reported prevalence rates of lifetime physical IPV between the two study years (AOR $=0.89 ; 95 \%$ CI 0.73 to 1.08 ).

12-month physical IPV prevalence: the 12-month prevalence of physical IPV decreased from 5\% in 2003 to $2.4 \%$ in $2019(\mathrm{OR}=0.46 ; 95 \%$ CI 0.27 to 0.79$)$. The AOR showed that, after controlling for sociodemographic factors, the decrease in 12-month physical IPV was attenuated but still remained significant $(\mathrm{AOR}=0.53 ; 95 \%$ CI 0.29 to 0.97$)$.

\section{Characteristics of women reporting lifetime and past- 12 month} physical IPV

Lifetime physical IPV: All sociodemographic factors were significantly associated with reporting lifetime physical IPV in the multivariate model, with the exception of 'access to independent income' and 'educational attainment'. Women aged 25 years and above were more likely to report having experienced at least one act of lifetime physical IPV. Compared with married women, a higher proportion of women who were cohabiting, divorced or widowed reported experiencing lifetime physical IPV. Similarly, those who were living in moderately or most deprived areas were more likely to report the experience of lifetime physical IPV compared with those living in the least deprived areas (table 2).

Past 12-month physical IPV: at the multivariate level, age and relationship status were significantly associated with reports of experiencing past 12-month physical IPV. A lower proportion of women aged 45 years and older reported experiencing past 12-month physical IPV compared with those younger than 45 years. A higher proportion of those who were cohabiting or divorced compared with those who were married reported this experience (table 2).

\section{Sexual IPV}

\section{Changes in sexual IPV prevalence rates}

Lifetime prevalence: a significant decrease in the reported lifetime prevalence of sexual IPV was found in the univariate analysis, from $16.9 \%$ in 2003 to $13.1 \%$ in 2019 ( $\mathrm{OR}=0.74 ; 95 \%$ CI 0.59 to 0.92 ). After controlling for sociodemographic variables, the significant decrease in the reported experience of lifetime sexual IPV remained unchanged (AOR $=0.74 ; 95 \%$ CI 0.59 to 0.95 ).

12-month prevalence: no significant differences in the 12-month prevalence rates of sexual IPV between the two study years was found in the univariate analysis (approximately $1 \%$ in both study years $)(\mathrm{OR}=0.50,95 \%$ CI 0.23 to 1.10). After controlling for sociodemographic factors, the non-significant difference in 12-month sexual IPV between two study years remained unchanged $(\mathrm{AOR}=0.50$; $95 \%$ CI to 0.19 to 1.35$)$.
Characteristics of women reporting lifetime and past 12 month sexual IPV

Lifetime sexual IPV: at the multivariate level, age, relationship status, education attainment and area-deprivation level were significantly associated with lifetime sexual IPV. Women were more likely to report having experienced lifetime sexual IPV if they were: aged 25 and over; cohabiting, divorced or separated, or widowed; or living in the most deprived areas. Those who had some tertiary education were less likely to report lifetime experience of sexual IPV compared with those with primary or secondary education (table 3 ).

Past 12-month sexual IPV: those who were divorced/ separated were more likely to report having experienced 12-month sexual IPV compared with married women. Those living in the most deprived areas were also more likely to report 12-month sexual IPV. Women aged 55 years and above were less likely to report having experienced sexual IPV in the past 12 months compared with younger women (table 3 ).

No significant interaction was found between study year and sociodemographic factors (data not shown).

\section{Changes in women's attitudes}

In 2003, 48.1\% agreed with at least one of the statements indicating agreement with traditional gender roles, compared with $38.4 \%$ in 2019 . While not common in 2003, it was even less common in 2019 for women to agree with the justifications for a man to hit his wife if he finds out she has been unfaithful (3.8\% agreement in 2003, $1.8 \%$ agreement in 2019; table 4).

\section{Changes in help-seeking behaviours}

There was an overall reduction in the proportion of women who had sought help from formal or informal sources, with three-quarters $(77 \%)$ of women who had experienced IPV reporting that they had told someone about the violence in 2003 compared with $70 \%$ in 2019. This reduction appears to be driven by the significant reduction in the proportion of women who sought help from informal sources (from $71.3 \%$ in 2003 to $64.6 \%$ in 2019). There was no change in the proportion of women who sought help from 'formal' sources between the two study years. Similarly, there was no significant change in the proportion of women who reported that they received help from formal sources (table 5).

\section{DISCUSSION}

Changes in prevalence of physical and sexual IPV between 2003 and 2019 were explored using two population-based surveys. Our findings indicated that the lifetime prevalence of physical IPV remained relatively unchanged between 2003 and 2019, with almost one-third (30\%) of women in both surveys reporting having experienced at least one act of physical IPV in their lifetime. This is similar to reported prevalence rates from the EU 28 -countries study (33\%), ${ }^{28}$ and the USA $(30.6 \%),{ }^{29}$ and 


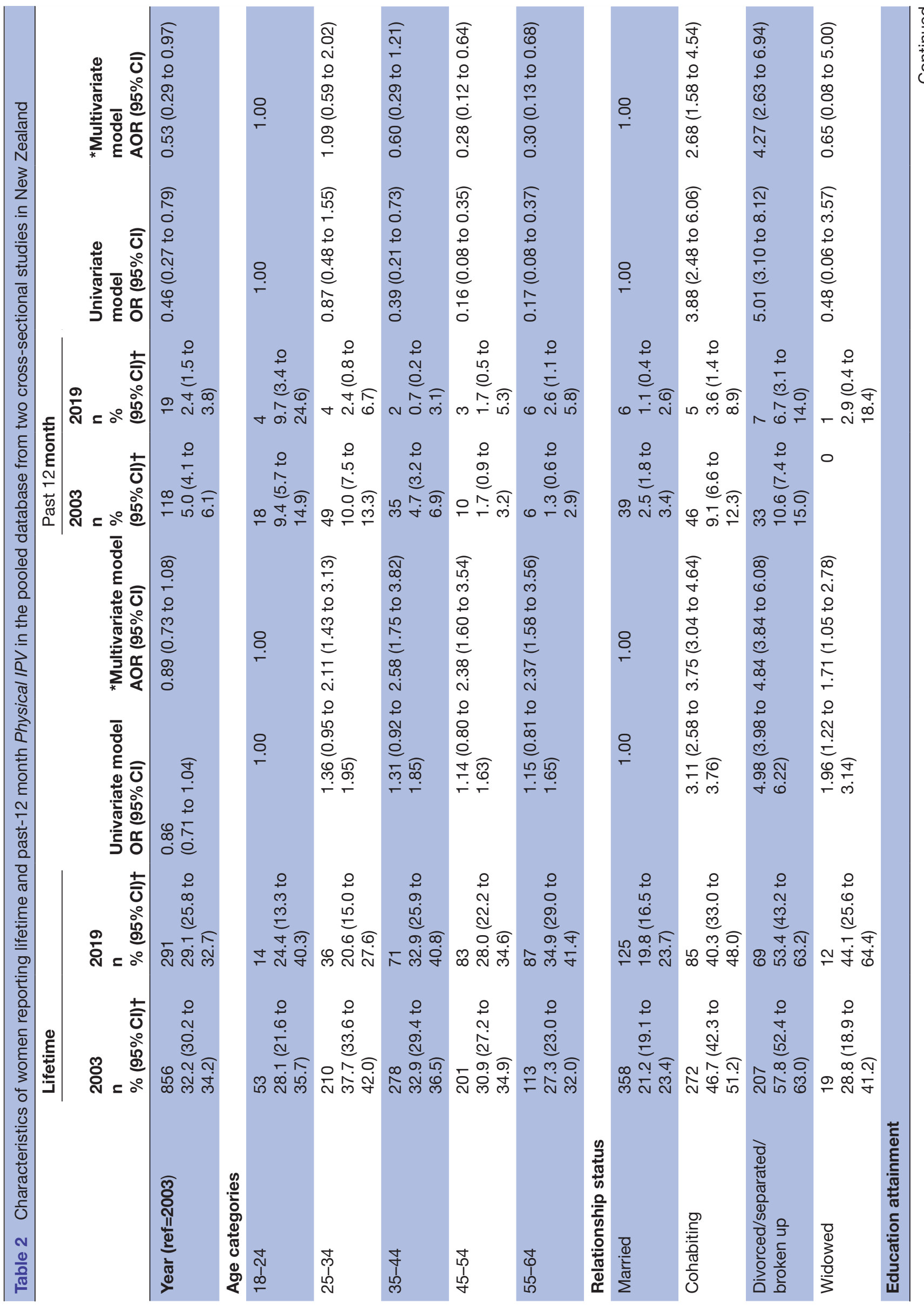




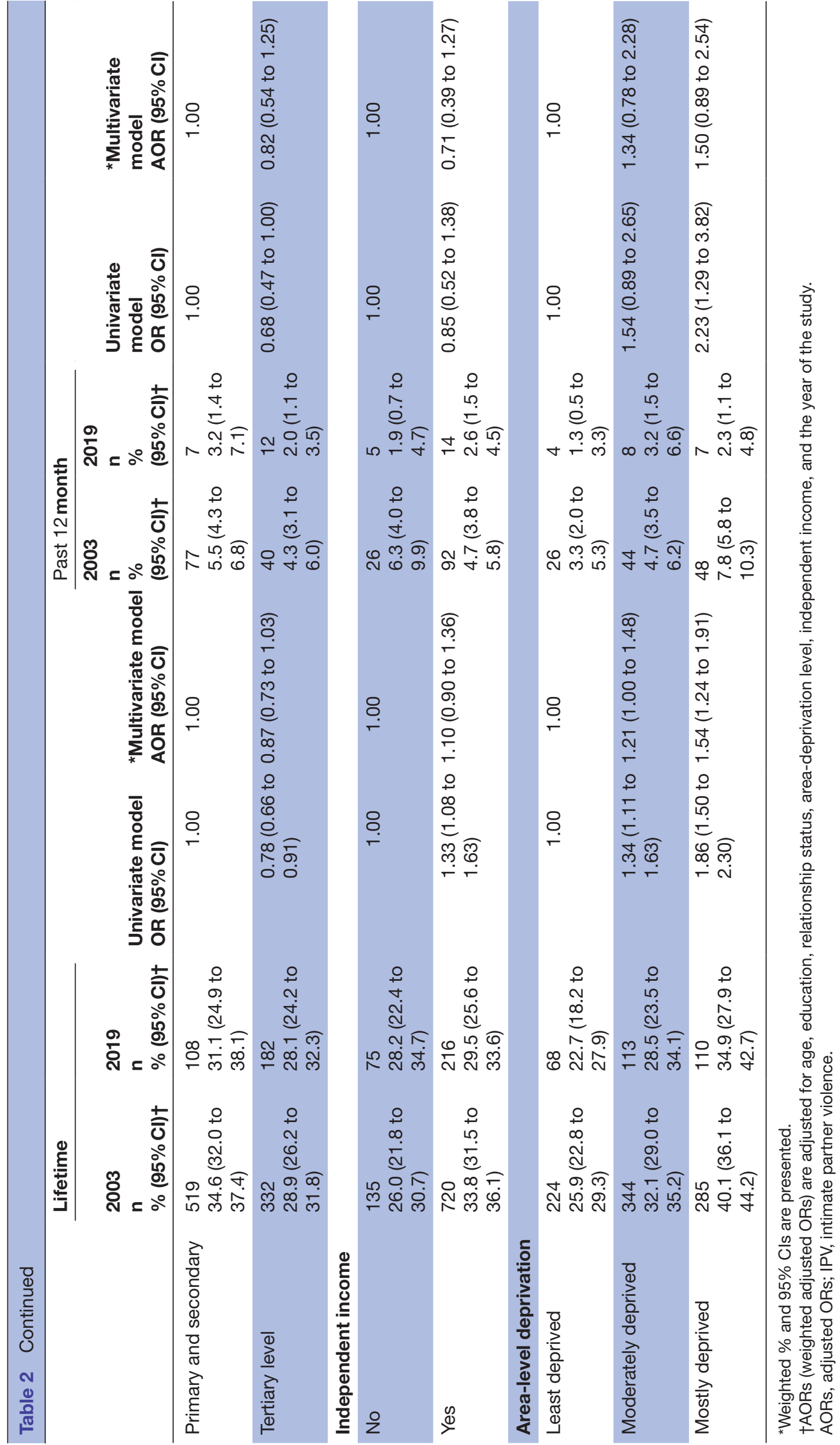




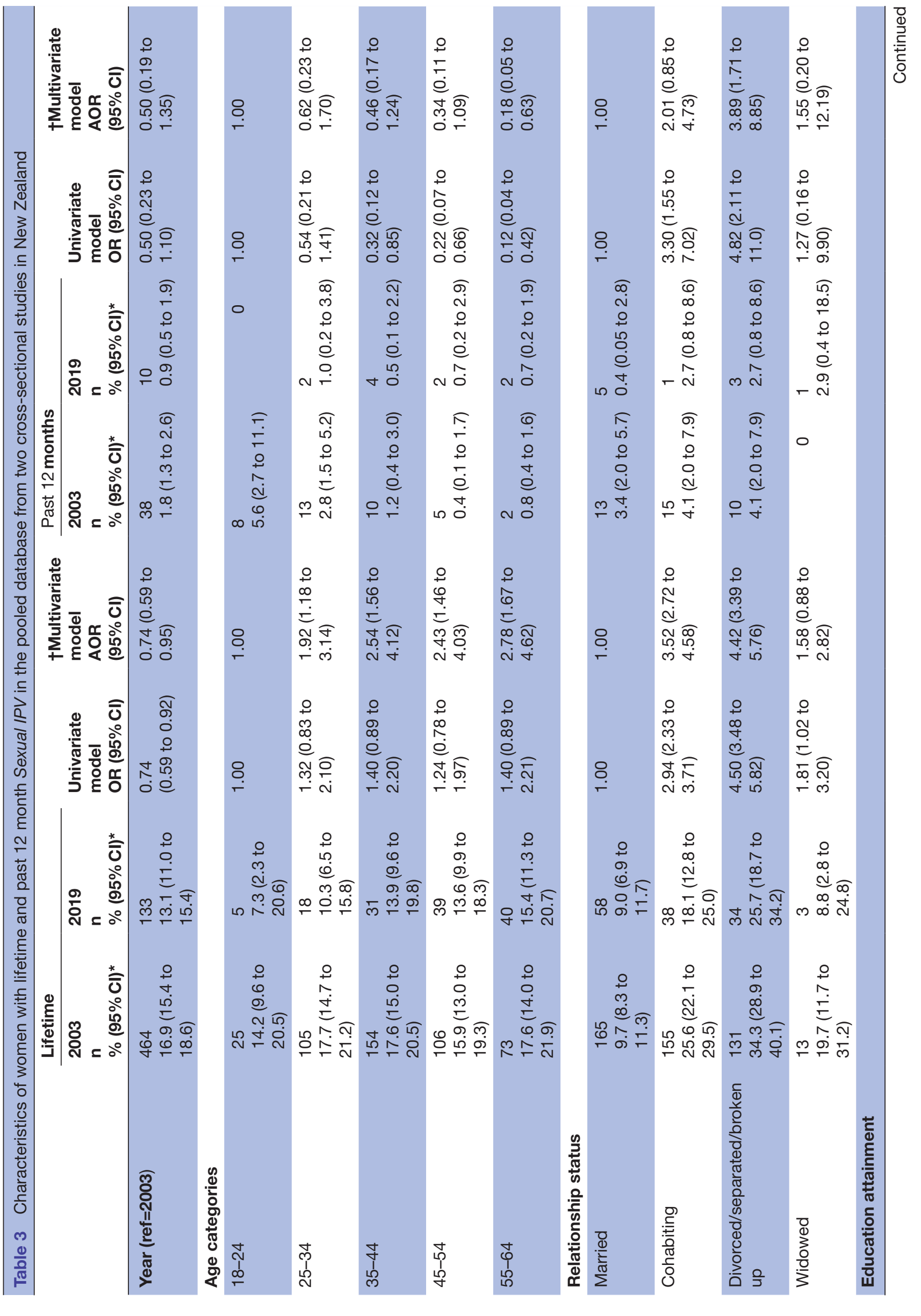




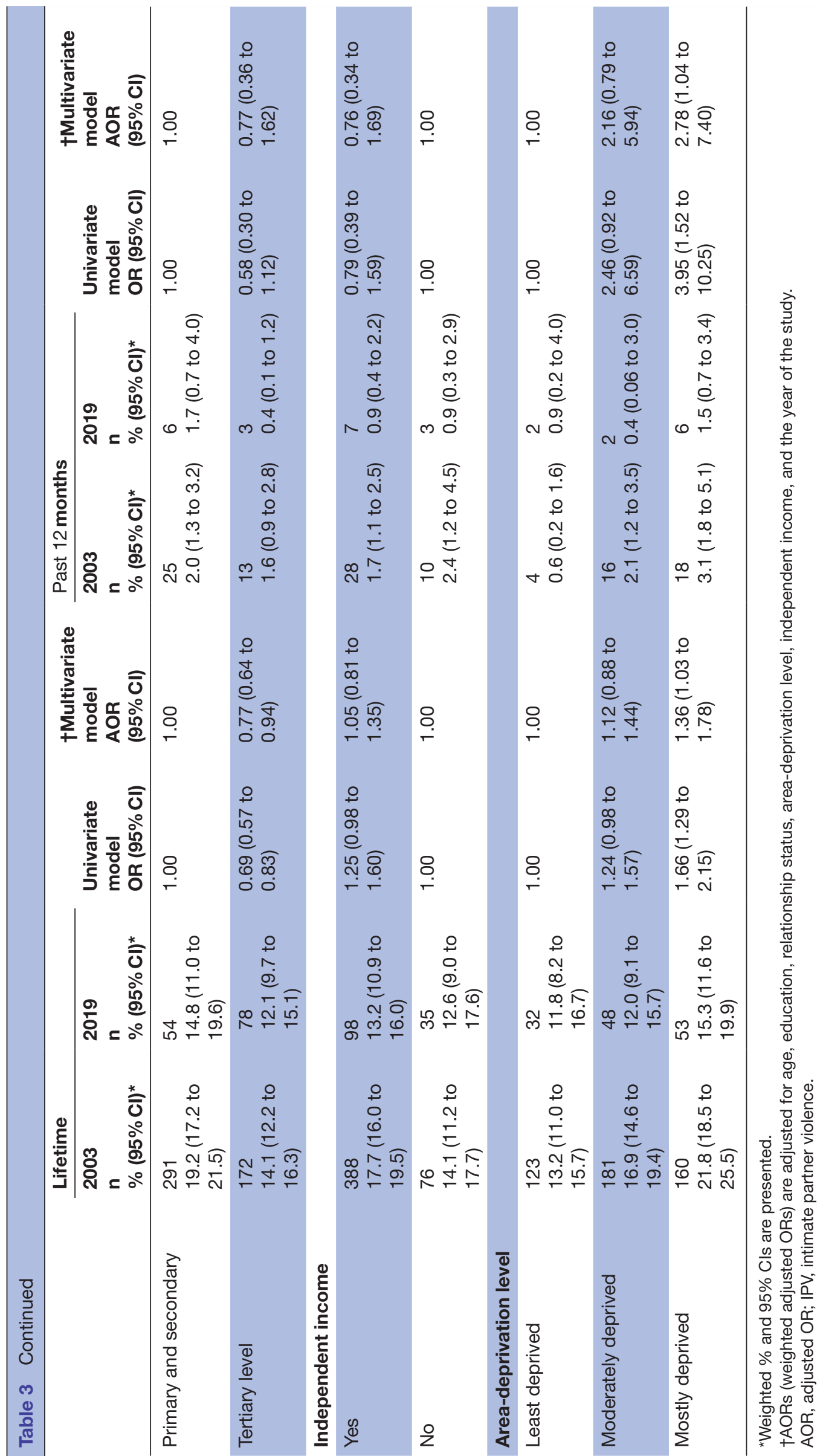


Table 4 Prevalence rates and changes in women's attitudes towards traditional gender roles in relationships and attitudes towards acceptability of a man hitting his wife

\begin{tabular}{|c|c|c|c|c|}
\hline \multirow[b]{2}{*}{ Attitude item } & \multicolumn{2}{|l|}{$\begin{array}{l}\text { Freq } \\
\%(95 \% \mathrm{Cl})^{\star}\end{array}$} & \multirow[t]{2}{*}{ Odds ratio $(95 \% \mathrm{Cl})^{*}$} & \multirow[t]{2}{*}{$P$ value } \\
\hline & $2003(n=2674)$ & $2019(n=944)$ & & \\
\hline \multicolumn{5}{|l|}{ Roles of women and men in relationships } \\
\hline $\begin{array}{l}\text { A good wife obeys her husband even if she } \\
\text { disagrees }\end{array}$ & $\begin{array}{l}371 \\
13.6(12.0 \text { to } 15.4)\end{array}$ & $\begin{array}{l}108 \\
14.7(10.8 \text { to } 19.8)\end{array}$ & $1.10(0.75$ to 1.61$)$ & 0.6 \\
\hline $\begin{array}{l}\text { Family problems should only be discussed } \\
\text { with people in the family }\end{array}$ & $\begin{array}{l}1076 \\
39.5 \text { (37.2 to } 41.9)\end{array}$ & $\begin{array}{l}274 \\
27.6(24.0 \text { to } 31.4)\end{array}$ & 0.58 (0.47 to 0.72$)$ & 0.001 \\
\hline $\begin{array}{l}\text { It is important for a man to show his partner } \\
\text { who is boss }\end{array}$ & $\begin{array}{l}201 \\
7.4(6.2 \text { to } 8.7)\end{array}$ & $\begin{array}{l}32 \\
3.1(2.1 \text { to } 4.7)\end{array}$ & $0.40(0.25$ to 0.64$)$ & 0.001 \\
\hline $\begin{array}{l}\text { A woman should be able to choose her own } \\
\text { friends even if her husband disapproves } \\
\text { (disagree) }\end{array}$ & $\begin{array}{l}169 \\
6.0(5.1 \text { to } 7.2)\end{array}$ & $\begin{array}{l}66 \\
7.3(5.5 \text { to } 9.6)\end{array}$ & $1.23(0.87$ to 1.74$)$ & 0.2 \\
\hline $\begin{array}{l}\text { It's a wife obligation to have sex with her } \\
\text { husband even if she doesn't feel like }\end{array}$ & $\begin{array}{l}216 \\
8.1(6.9 \text { to } 9.4)\end{array}$ & $\begin{array}{l}56 \\
5.8(4.1 \text { to } 8.0)\end{array}$ & 0.70 (0.47 to 1.03$)$ & 0.07 \\
\hline Agreed with at least one statement & $\begin{array}{l}1337 \\
48.1(45.7 \text { to } 50.5)\end{array}$ & $\begin{array}{l}365 \\
38.4 \text { (33.8 to } 43.2)\end{array}$ & 0.67 (0.54 to 0.83$)$ & 0.001 \\
\hline \multicolumn{5}{|l|}{ Acceptability of a man hitting his wife } \\
\hline $\begin{array}{l}\text { She doesn't complete her household work to } \\
\text { his satisfaction }\end{array}$ & $\begin{array}{l}9 \\
0.3(0.1 \text { to } 0.6)\end{array}$ & $\begin{array}{l}5 \\
0.4(0.1 \text { to } 1.2)\end{array}$ & $1.47(0.40$ to 5.36$)$ & 0.5 \\
\hline She disobeys him & $\begin{array}{l}18 \\
0.5(0.3 \text { to } 0.9)\end{array}$ & $\begin{array}{l}8 \\
0.7(0.3 \text { to } 1.5)\end{array}$ & 1.32 (0.52 to 3.34$)$ & 0.5 \\
\hline She refuses to have sex with him & $\begin{array}{l}9 \\
0.2(0.1 \text { to } 0.5)\end{array}$ & $\begin{array}{l}5 \\
0.5(0.2 \text { to } 1.3)\end{array}$ & 1.99 (0.60 to 6.62$)$ & 0.2 \\
\hline She asks him whether he has other girlfriends & $\begin{array}{l}18 \\
0.5(0.3 \text { to } 1.0)\end{array}$ & $\begin{array}{l}3 \\
0.2(0.04 \text { to } 0.7)\end{array}$ & 0.31 (0.07 to 1.39$)$ & 0.1 \\
\hline He suspects that she is unfaithful & $\begin{array}{l}36 \\
1.3(0.9 \text { to } 1.9)\end{array}$ & $\begin{array}{l}8 \\
0.7(0.3 \text { to } 1.5)\end{array}$ & $0.52(0.22$ to 1.25$)$ & 0.1 \\
\hline He finds out she has been unfaithful & $\begin{array}{l}107 \\
3.8(3.0 \text { to } 4.8)\end{array}$ & $\begin{array}{l}17 \\
1.8(1.0 \text { to } 3.3)\end{array}$ & $0.46(0.24$ to 0.90$)$ & 0.02 \\
\hline Agreed with at least one statement & $\begin{array}{l}107 \\
3.5(2.8 \text { to } 4.5)\end{array}$ & $\begin{array}{l}22 \\
2.3(1.4 \text { to } 3.8)\end{array}$ & $0.64(0.35$ to 0.1 .14$)$ & 0.1 \\
\hline
\end{tabular}

*Weighted \% and ORs with 95\% Cls are presented.

is comparable to the global average.$^{30}$ While lifetime prevalence of physical IPV was unchanged, there was a significant decrease in the proportion of women who reported experiencing 12-month physical IPV. Small reductions in rates for lifetime sexual IPV were also observed. Population changes in sociodemographic characteristics did not fully explain the decreases in IPV prevalence over time, and the noted changes were consistent across sub-groups of the population.

In 2003, $48.1 \%$ of women agreed with one or more of the statements supportive of traditional gender roles, compared with $38.4 \%$ in 2019 . These were low percentages of agreement compared with women in low-income and middle-income countries. ${ }^{31-33}$ Agreement with attitudes supportive of justifications for a man hitting his wife was low in both the $2003(0.2 \%-3.8 \%)$ and 2019 surveys $(0.2 \%-2.3 \%)$, and extremely low compared with results reported from low-and middle-income countries. ${ }^{34}{ }^{35}$ but comparable with high income countries. ${ }^{36}$ Even with this low rate of agreement, change was still observed, with a significant reduction in agreement with the statement that 'it is acceptable for a man to hit his wife if he found out she was unfaithful', from $3.8 \%$ in 2003 to $1.8 \%$ in 2019.

Overall, among women who experienced IPV, the rates of disclosure (telling someone about the violence) were high $(77 \%$ in $2003,70 \%$ in 2019$)$, compared with findings from low-income and middle-income countries, ${ }^{3738}$ and comparable with high-income countries. ${ }^{39}$ It should be noted, however, that most disclosures were made to informal sources, such as family or friends. There was no change in 'help received' from formal sources $(21.1 \%$ in $2003,19.4 \%$ in 2019$)$. This warrants further attention, to determine if this is due to limited service capacity, or limits in the quality of help currently available. 
更

व

क्षे

늘

운

ֻ

ฮิ

空

要

离

Фิ

这

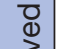

:

$\frac{\circ}{0}$

들

蒙

을

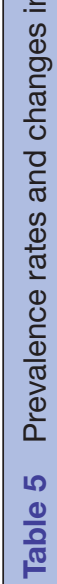
空

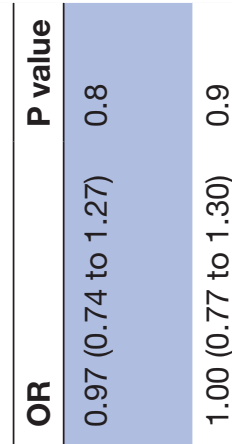

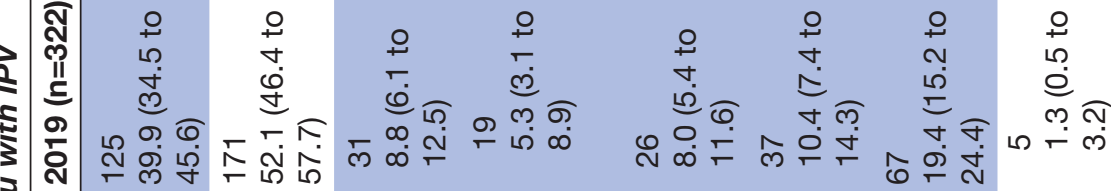

$\infty$

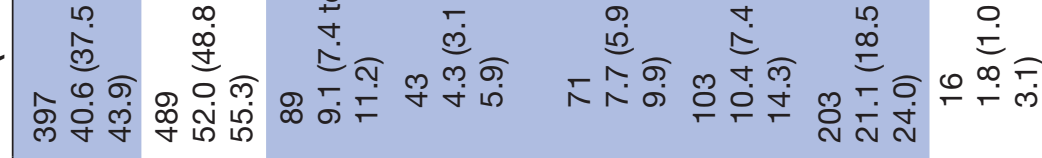

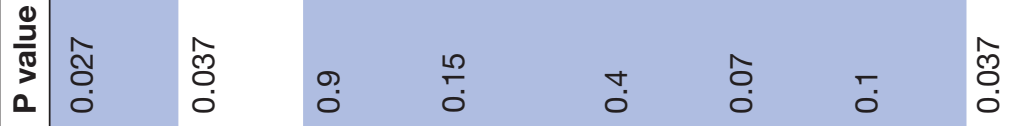

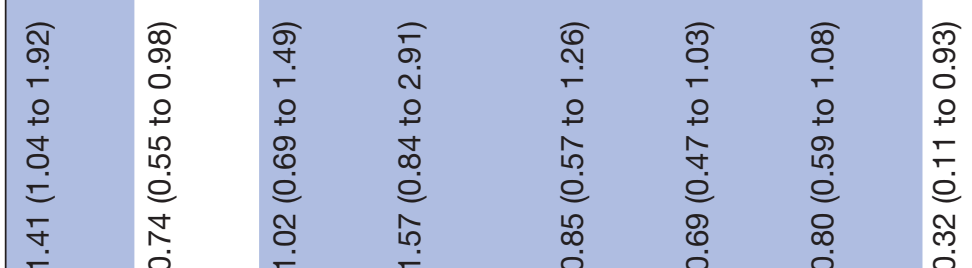

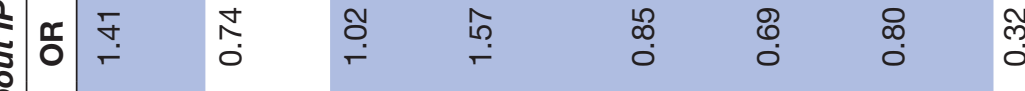

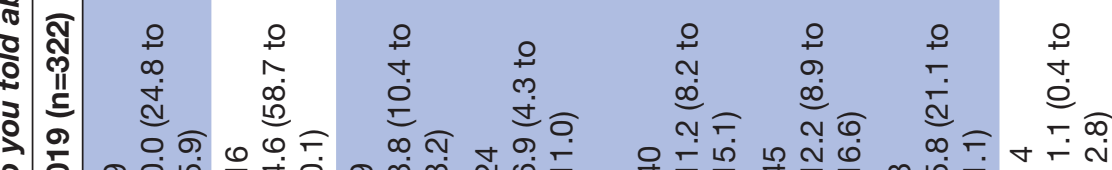

定

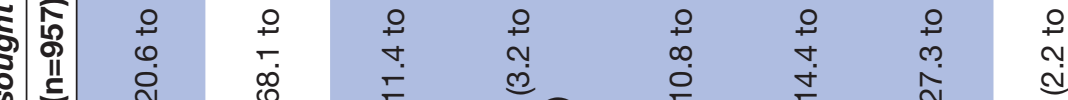

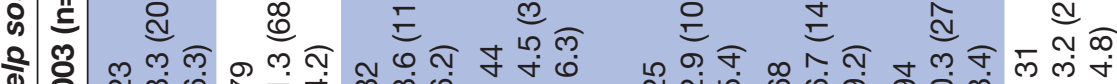
至 N

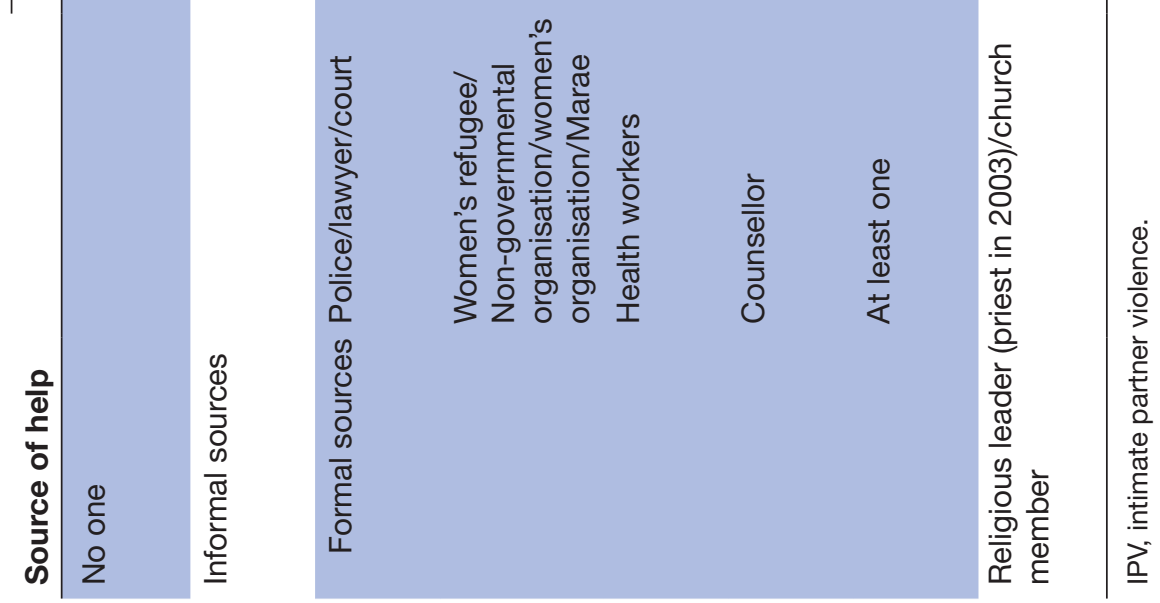


Possible explanations for the study findings include: actual changes in perpetrator behaviour over time; or changes due to differences in methods, measurement or samples.

There is some evidence that changes in perpetrator behaviour may have occurred, as the reduction in the 12-month prevalence of physical and lifetime sexual IPV between 2003 and 2019 is consistent with a reduction in 12-month prevalence of psychological IPV noted in the same sample. ${ }^{40}$ Changes in perpetrator behaviour are possible, as there have been a series of strategies and campaigns implemented between the two study years. These included: changes in legislation (eg, amendments to family violence law), and the introduction of prevention campaigns and programmes (eg, the Family Violence: It's not ok national campaign, ${ }^{41}$ and the Accident Compensation Corporation-funded Mates and Dates high schools programmes on healthy relationships ${ }^{42}$ ). These actions may have contributed to changes in societal awareness and understandings of attitudes supportive of violence against women as there is some evidence that these initiatives had wide population reach. ${ }^{40}$ This interpretation is supported by our findings on the reduction in women's agreement with attitudes towards traditional gender roles and reduction in women's agreement with the acceptability of a man hitting his wife if she was unfaithful. Other studies have also noted the relationship between attitudes to violence and victimisation. ${ }^{43} 44$

An additional feature of these societal actions was the call for those experiencing violence to reach out for help. ${ }^{41}$ Our findings suggest that there has been no change in women contacting formal sources of help, and a small but significant reduction in talking with informal sources. As help seeking can be related to the severity of violence experienced, it is possible that the lack of change in accessing formal help among women is related to the reduction of current physical, and lifetime sexual IPV between the studied years and a possible decrease of high severity cases. However, it is also possible that activities designed to encourage community engagement in violence prevention may need additional resourcing to ensure a sustained response and appropriate access to necessary services. Further research with larger sample sizes will be important to verify this finding.

The alternate explanation of the observed changes being due to differences in study methods or sample difference seem less likely. Specifically, the comparability of methods across the two surveys, including use of identical questions in the two survey waves, lends strength to the interpretation that the prevalence changes noted are real. Additionally, while there were some differences in the characteristics of the two samples, the AOR showed that after controlling for all sociodemographic factors, the observed differences in prevalence still remained significant.

The observed reduction in 12-month prevalence of physical IPV is positive, and parallels overall reductions in crime rates reported by crime and victimisation surveys ${ }^{45}$ and is similar to reductions in prevalence of IPV documented in Australia between 1996 and 2005. ${ }^{46}$ It may be the result of more women recognising abusive behaviour and taking their own actions to leave abusive relationships. However, further efforts and investment are needed to ensure that those who ask for help actually receive help. Importantly, the stability of the lifetime prevalence of physical IPV should heighten efforts to develop and implement comprehensive and sustained prevention work with those who use violence in relationships.

\section{Strengths}

Strengths include: the representativeness of the samples obtained, and the use of comparable methods and comparable questions across the two survey waves. Additionally, the 15-year time gap between the two survey waves is sufficient to determine if real change occurred. ${ }^{12}$

\section{Limitations and recommendations for future studies}

Changes between two time points are not sufficient to determine if the change represents a trend, so caution is needed when interpreting the changes observed. Overall, the prevalence estimates obtained may under-report what is happening in the population as a whole, either because of stigma, ${ }^{47}$ or because of the overall response rate for the study. While we successfully surveyed over $63 \%$ of eligible women, those with greater levels of exposure to violence may be less likely to have participated. Future studies would benefit from larger sample sizes, which would improve the chance of detecting real changes in low base rate phenomena, such as 12-month prevalence of sexual IPV.

\section{CONCLUSION}

The observed reduction in 12-month physical and lifetime sexual IPV prevalence rates, changes in attitudes about the acceptability of violence, and the increases in help seeking are positive. However, work is still needed to address the substantial problem of IPV, as the lifetime prevalence rate of one in three women experiencing IPV remained stable over the 15 -year time interval. This means that prevention efforts must be increased and sustained, and that adequate structures and resources must be available to respond to those seeking help.

\section{Author affiliations \\ ${ }^{1}$ School of Population Health, The University of Auckland Faculty of Medical and Health Sciences, Auckland, New Zealand \\ ${ }^{2}$ School of Māori Studies and Pacific Studies, Faculty of Arts, The University of Auckland Faculty of Arts, Auckland, New Zealand}

Acknowledgements The authors gratefully acknowledge participants, the interviewers and the study project team, led by Patricia Meagher-Lundberg. They also acknowledge the representatives from the Ministry of Justice, the Accident Compensation Corporation, the New Zealand Police, and the Ministry of Education, who were part of the Governance Group for Family and Sexual Violence at the inception of the study. The two cross-sectional studies from which this study used data are based on the WHO Violence Against Women Instrument as developed for use in the WHO Multi-Country Study on Women's Health and Domestic Violence and 
has been adapted from the version used in Asia and the Pacific by kNOWVAWdata (V.12.03).

Contributors JF and PG contributed to the conception and design of the study. TM contributed to the application for funding of 2019 study. LH managed the data cleaning, and conducted the analyses, with contributions from ZM. LH, JF, ZM and PG interpreted the data, drafted the article and revised it. All authors contributed to the manuscript and approved the final version.

Funding This work was supported by the Health Research Council of New Zealand (Grant 02/207) for the 2003 study and the New Zealand Ministry of Business, Innovation and Employment, Contract number CONT-42799-HASTR-UOA for the 2019 study.

\section{Competing interests None declared.}

Patient consent for publication Not required.

Ethics approval Ethics approval was granted by the University of Auckland Human Participants Ethics Committee in 2003 (Ref number: 2002/199) and 2019 (Reference number 2015/ 018244).

Provenance and peer review Not commissioned; externally peer reviewed.

Data availability statement № data are available. Data are unavailable due to the confidentiality and sensitivity of the data and Māori data sovereignty.

Supplemental material This content has been supplied by the author(s). It has not been vetted by BMJ Publishing Group Limited (BMJ) and may not have been peer-reviewed. Any opinions or recommendations discussed are solely those of the author(s) and are not endorsed by BMJ. BMJ disclaims all liability and responsibility arising from any reliance placed on the content. Where the content includes any translated material, BMJ does not warrant the accuracy and reliability of the translations (including but not limited to local regulations, clinical guidelines, terminology, drug names and drug dosages), and is not responsible for any error and/or omissions arising from translation and adaptation or otherwise.

Open access This is an open access article distributed in accordance with the Creative Commons Attribution Non Commercial (CC BY-NC 4.0) license, which permits others to distribute, remix, adapt, build upon this work non-commercially, and license their derivative works on different terms, provided the original work is properly cited, appropriate credit is given, any changes made indicated, and the use is non-commercial. See: http://creativecommons.org/licenses/by-nc/4.0/.

ORCID iD

Janet Fanslow http://orcid.org/0000-0001-6511-0655

\section{REFERENCES}

1 United Nations. Secretary-General's in-depth study on all forms of violence against women, in Report of the Secretary-General. U.N. document A/61/122/Add.1, 2006.

2 Kangaspunta K, Marshall IH. Trends in Violence against Women: Some Good News and Some Bad News. In: Jan van Dijk AT, Farrell G, eds. The International crime drop. London: Palgrave Macmillan, 2012: 103-55.

3 Gulliver P, Fanslow J. Measurement of family violence at a population level: : What might be needed to develop reliable and valid family violence indicators? New Zealand Family Violence Clearinghouse: New Zealand, 2012.

4 Powers RA, Kaukinen CE. Trends in intimate partner violence: 19802008. J Interpers Violence 2012;27:3072-90.

5 Orr C, Preen D, Fisher C, et al. Trends in hospital admissions for intimate partner violence in Australian mothers with children born from 1990 to 2009. J Interpers Violence 2019;0886260519832905:08 8626051983290.

6 United_Nations. The World's Women 2010: Trends and Statistics, in UN Stats, 2010.

7 Tjaden P, Thoennes N. Prevalence, incidence, and consequences of violence against women: findings from the National violence against women survey. Washington, U.S.A: U.S. Department of Justice, Office of Justice Programs, National Institute of Justice, 1998.

8 Canada S. The violence against women survey. Canada: Highlights, in Dly Stat Can, 1993: 1-9.

9 Mouzos J, Makkai T. Women's Experiences of Male Violence: Findings from the Australian Component of the International Violence Against Women Survey (IVAWS), R.a.P.P. Series, Editor. 162. Australia. p: Australian Institute of Criminology, 2004.

10 FRA-European Union Agency for Fundamental Rights. Violence against women: an EU-wide survey. European Union Agency for Fundamental Rights: Luxembourg: Publications Office of the European Union, 2015

11 Heiskanen M, Piispa M, Faith H. Battering: A Survey of Men's Violence Against Women in Finland. Helsinki: Yliopistopaino, 1998

12 Heiskanen M, Piispa M. Violence against women in Finland. results from two national Victimisation surveys. in VICTIMISATION surveys in comparative perspective. Stockholm: European Institute for Crime Prevention and Control, affiliated with the United Nations (HEUNI) P.O.Box 444 FIN-00531 Helsinki Finland, 2007.

13 Sanz-Barbero B, Barón N, Vives-Cases C. Prevalence, associated factors and health impact of intimate partner violence against women in different life stages. PLoS One 2019;14:e0221049.

14 Fanslow J, Robinson E. Violence against women in New Zealand: prevalence and health consequences. N Z Med J 2004;117:U1173.

15 Dahlberg LL, Krug EG. Violence a global public health problem, 2006. Available: http://www.scielo.br/scielo.php?script=sci_arttext\&pid= S1413-81232006000200007\&nrm=iso

16 Heise LL. Violence Against Women:An Integrated. Ecological Framework 1998;4:262-90.

$17 \mathrm{Kim}$ JY, Oh S, Nam SI. Prevalence and trends in domestic violence in South Korea: findings from national surveys. $J$ Interpers Violence 2016;31:1554-76.

18 Dawson M, Bunge VP, Balde T. National trends in intimate partner homicides: explaining declines in Canada, 1976 to 2001. Violence Against Women 2009;15:276-306.

19 Hindin MJ. Understanding women's attitudes towards wife beating in Zimbabwe / Michelle J. Hindin. Bulletin of the World Health Organization : the International Journal of Public Health 2003;81:501-8.

20 Koenig MA, Stephenson R, Ahmed S, et al. Individual and contextual determinants of domestic violence in North India. Am J Public Health 2006;96:132-8

21 World Health O. Changing cultural and social norms that support violence. Geneva: World Health Organization, 2009.

22 Donovan RJ, Paterson D, Francas M. Targeting male perpetrators of intimate partner violence: Western Australia's "Freedom from Fear" campaign. Soc Mar Q 1999;5:128-44.

23 Usdin S, Scheepers E, Goldstein S, et al. Achieving social change on gender-based violence: a report on the impact evaluation of soul City's fourth series. Soc Sci Med 2005;61:2434-45.

24 Fanslow J, Gulliver P, Hashemi L. Methods for the 2019 New Zealand family violence study- a study on the association between violence exposure, health and well-being. New Zealand Journal of Social Sciences Online 2021:1-14.

25 WHO. Putting women first: ethical and safety recommendations for research on domestic violence against women. Geneva, Switzerland: Department of Gender and Women's Health, Family and Community Health, World Health Organization, 2001.

26 Core Technical Team, W.M.-c.S.o.V.A.W. Who multicountry study on violence against women, questionnaire, version 10. WHO: Gender and Health Department, 2003.

27 StataCorp. Stata statistical software: release 15. College Station, TX: StataCorp LLC, 2017.

28 Goodey J. Violence against women: placing evidence from a European Union-Wide survey in a policy context. $J$ Interpers Violence 2017;32:1760-91.

29 Smith SG, Zhang X, Basile KC, et al. National intimate partner and sexual violence survey: 2015 data brief - updated release. Atlanta, Georgia: National Center for Injury Prevention and Control, Centers for Disease Control and Prevention, 2018.

30 WHO. Global and regional estimates of violence against women: prevalence and health effects of intimate partner violence and nonpartner sexual violence. Italy: World Health Organization, 2013.

31 Jayatilleke A, Poudel KC, Sakisaka K, et al. Wives' attitudes toward gender roles and their experience of intimate partner violence by husbands in central Province, Sri Lanka. J Interpers Violence 2011;26:414-32.

32 Hayati EN, Högberg U, Hakimi M, et al. Behind the silence of harmony: risk factors for physical and sexual violence among women in rural Indonesia. BMC Womens Health 2011:11:52.

33 Black E, Worth H, Clarke S, et al. Prevalence and correlates of intimate partner violence against women in conflict affected Northern Uganda: a cross-sectional study. Confl Health 2019;13:35.

34 Khan MN, Islam MM. Women's attitude towards wife-beating and its relationship with reproductive healthcare seeking behavior: a countrywide population survey in Bangladesh. PLoS One 2018;13:e0198833.

35 Hindin MJ. Understanding women's attitudes towards wife beating in Zimbabwe. Bull World Health Organ 2003;81:p. 501-8.

$36 \mathrm{VicHealth}$. Australians' attitudes to violence against women. Australia: Victorian Health Promotion Foundation, 2014. 
37 Leonardsson M, San Sebastian M. Prevalence and predictors of help-seeking for women exposed to spousal violence in India - a cross-sectional study. BMC Womens Health 2017;17:99.

38 Linos N, Slopen N, Berkman L, et al. Predictors of help-seeking behaviour among women exposed to violence in Nigeria: a multilevel analysis to evaluate the impact of contextual and individual factors. $J$ Epidemiol Community Health 2014;68:211-7.

39 Ansara DL, Hindin MJ. Formal and informal help-seeking associated with women's and men's experiences of intimate partner violence in Canada. Soc Sci Med 2010;70:1011-8.

40 Fanslow JL, Malihi Z, Hashemi L. Change in prevalence of psychological and economic abuse, and controlling behaviours against women by an intimate partner in two cross-sectional studies in New Zealand, 2003-2019. BMJ Open.

41 Roguski M. 'It's not OK' Campaign Community Evaluation Project 2015. New Zealand: New Zealand Ministry of Social Development.
42 Duncan A, Kingi V. Evaluation of ACC's Mates and Dates : : schoolbased healthy relationships primary prevention programme pilot. Wellington, New Zealand: Lighthouse Consulting New Zealand, 2015.

43 Khawaja M, Linos N, El-Roueiheb Z. Attitudes of men and women towards wife beating: findings from Palestinian refugee camps in Jordan. J Fam Violence 2008;23:211-8.

44 Nayak MB, Byrne CA, Martin MK, et al. Attitudes toward violence against women: a Cross-Nation study. Sex Roles 2003;49:333-42.

45 Mayhew P. The Case of Australia and New Zealand. In: Farrell JvDATG, ed. The International crime drop -2012 new directions in research. 2012, Palgrave Macmillan, a division of Macmillan Publishers Limited, 2012: 76-102.

464906.0 - Personal Safety, Australia, 2012 (abs.gov.au). Available: Personal Safety Survey 2012: changes in prevalence of partner violence over time [Accessed 19 March 2021].

47 Gracia E. Unreported cases of domestic violence against women: towards an epidemiology of social silence, tolerance, and inhibition. J Epidemiol Community Health 2004;58:536-7. 